\title{
A Contingent Perspective on Pluralistic Ignorance: When the Attitudinal Object Matters
}

\section{Léila Eisner $\mathbb{1}^{\mathrm{I}, 2}$, Dario Spini ${ }^{\mathrm{I}, 2}$, and Nicolas Sommet ${ }^{\mathrm{I}, 2}$}

\begin{abstract}
${ }^{\mathrm{I}}$ Institute of Social Sciences, University of Lausanne, Lausanne, Suisse; ${ }^{2}$ Swiss National Centre of Competence in Research LIVES-Overcoming Vulnerability: Life Course Perspectives, University of Lausanne, Lausanne, Suisse
\end{abstract}

\begin{abstract}
Although past research has suggested that pluralistic ignorance-a mismatch between perceptions of others' opinions and actual personal opinions - does not occur in every circumstance, no studies have directly investigated variations among different attitude objects. Drawing upon theoretical and analytical approaches based on social representations, this study examines differences between personal opinions and perceived opinions of different groups toward same-sex female parenting (a newly debated attitude object) and working mothers (an older debated attitude object). Using data from a study $(N=743)$ conducted in Switzerland, the findings indicate that pluralistic ignorance occurs in opinions toward same-sex female parenting. Furthermore, the findings show that pluralistic ignorance arises from false consensus among conservatives and from false uniqueness among liberals.
\end{abstract}

One of the most common findings in social psychology and public opinion research is the mismatch between perceptions of others' opinions and actual personal opinions, which is known as pluralistic ignorance (Eveland \& Glynn, 2008). While some people, often conservatives, overestimate how widely their own opinions are shared, others, often liberals, wrongly believe that their own opinions differ greatly from those of others (Stern, West, \& Schmitt, 20I4). It has been suggested, though not empirically tested, that mismatches between perceived others' opinions and actual personal opinions do not occur in every circumstance, as they "only hold sway over a society for a limited period of

All correspondence concerning this article should be addressed to Léila Eisner, M.A., University of Lausanne, Geopolis Building, 1015 Lausanne, Suisse. E-mail: leila.eisner@unil.ch 
time" (Noelle-Neumann \& Petersen, 2004, p. 350). Arguably, pluralistic ignorance is more likely to occur with debated attitude objects "by which the individual isolates or may isolate himself in public" (Noelle-Neumann, I983, p. I4I). Despite these suggestions, to our knowledge, no studies have directly investigated the circumstances under which pluralistic ignorance is more likely to occur. To adress this issue, we measure perceived opinions related to different reference groups (e.g., most people or most friends and relatives) and personal opinions about new or older debates.

In the present research, we draw upon a social representation (SR) approach (Moscovici, I976; Sammut, Andreouli, Gaskell, \& Valsiner, 2015) to classify individuals based on their social positioning (i.e., differences between opinions and perceptions of different nested groups' opinions) toward samesex female parenting (a newly debated attitude object) and working mothers (an older and more agreed-upon attitude object). We consider that individuals' opinions toward an object and their perceptions of others' opinions are contingent on a broader context in which representations have contextual, historical, and practical anchoring (Elejabarrieta, I994). On this basis, we propose that pluralistic ignorance is present mainly in newly debated objects. Moreover, as opinions and perceptions are part of a social metasystem linked to conflict and political agendas (Elcheroth, Doise, \& Reicher, 20I I), conservatives and liberals may hold strategic positions regarding the future of the debate. Therefore, we suggest that pluralistic ignorance might occur in a specific normative window of time "where the prevailing norms are neither entirely positive nor entirely negative toward the groups, but where there is a general social change toward greater acceptance of the group" (Crandall \& Warner, 2005, p. I38).

\section{Pluralistic Ignorance, False Consensus, and False Uniqueness}

Since the first studies on students' attitudes (Katz \& Allport, I93 I), the concept of pluralistic ignorance has been supported for various "controversial" attitude objects, such as race (Fields \& Schuman, 1976), drinking behavior (Prentice \& Miller, I993), sexual minorities (Bowen \& Bourgeois, 200I), or sexual intercourse (Cohen \& Shotland, I996). Pluralistic ignorance has also been shown to occur for various groups of reference, such as most people, friends, or neighbors (e.g., Fields \& Schuman, I976; Glynn, I989).

Pluralistic ignorance refers to a situation in which individuals perceive that their opinion is shared by the minority when it is in fact shared by the majority (Katz \& Allport, I93I), or vice versa (Merton, I968). In this article, we endorse an expanded definition of pluralistic ignorance by focusing on the perceived self-other distance. We focus on the perceived difference between personal opinions and the opinions of others rather than the factual accuracy of perceptions of others' opinions. 
According to this expanded definition, pluralistic ignorance is a cognitive bias that can have two directions (Eveland \& Glynn, 2008; O'Gorman, I988). The first is false consensus, whereby one has the tendency to falsely consider his or her opinion as commonly shared and alternative views as uncommon or deviant (Eveland \& Glynn, 2008; Miller \& McFarland, I987; Ross, Greene, \& House, 1977). The second is false uniqueness, whereby one has the tendency to falsely consider his or her opinion as unique and not shared by others (Bosveld, Koomen, van der Pligt, \& Plaisier, I995; Stern et al., 20I4).

Two underlying mechanisms explain false consensus and-to a lesser extent-false uniqueness. The first is a cognitive mechanism arising from a lack of information to make people realize that their personal opinion is much more/less shared than what they think. The second is a motivational mechanism arising from ego-defensive motivations through which people justify their personal opinion (Gross \& Miller, I997; Marks \& Miller, I987; Mullen \& Hu, I988; Wojcieszak, 2008; Wojcieszak \& Price, 2009). However, while both cognitive and motivational mechanisms may explain false consensus and false uniqueness, they are so intertwined that it is difficult to distinguish between them.

In the literature, false consensus and false uniqueness have been linked to political values. Research indicates that conservative values are a predictor of false consensus. People scoring high in conservative values showed greater social projection regarding political attitudes (i.e., false consensus), which was accounted for by a higher need for closure (Amit, Roccas, \& Meidan, 2010). Moreover, European Americans scoring high in right-wing authoritarianism and social dominance orientation were more likely to express false consensus in evaluating opinions toward African Americans (Strube \& Rahimi, 2006). Several studies have shown that right-wing supporters tend to express false consensus, especially when they see that support for their opinion declines (e.g., Dvir-Gvirsman, 2015; Reid \& Hogg, 2005).

In contrast, research indicates that the endorsement of liberal values is a predictor of false uniqueness. In a study of Israeli voters, extreme left-wing supporters had a tendency for false uniqueness, which might be explained by their motivation to be perceived as a unique minority and distinct from conventional right-wing voters (Babad \& Yacobos, I993). Moreover, liberals tended to underestimate their similarity with other people due to their desire to feel unique (Rabinowitz, Latella, Stern, \& Jost, 20ı6; Stern, West, \& Schmitt, 2014).

Whereas the social and temporal contexts around the attitude object are often implicitly considered in the justification for false consensus and false uniqueness, the idea that the activation of false consensus and false uniqueness among right-wing and left-wing supporters might vary for different objects has, to our knowledge, never been tested. In this article, we rely on a SR 
approach (Sammut et al., 2015) to study the phenomena of pluralistic ignorance, false consensus, and false uniqueness for attitude objects that differ in their novelty in the public debate.

\section{Toward a Social Representational Understanding of Pluralistic Ignorance, False Consensus, and False Uniqueness}

Social representations are ideas, thoughts, images, and knowledge that are collectively shared (Moscovici, I988, I99I; Sammut et al., 2015). They are created when an object is newly inserted into the public sphere or becomes an issue in a given context. In such situations, individuals tend to develop representations of what other groups believe (Wagner, I995) and position themselves toward these representations. This action is social positioning, which is the "process by which people take up a position about a network of significations" (Clémence, 200I, p. 83). More broadly, social positioning is the result of the adaptation between what we think and what other groups think (Clémence, 200I).

Social positioning may vary depending on the group to which people refer when taking positions. In particular, the level of closeness to different groups of reference might influence pluralistic ignorance. It is conceivable that people perceive larger self-other disparities with general others (e.g., most people) than with close others (e.g., friends). This finding is consistent with findings from research on the "third-person effect," which focuses on the perceived impact of mass media messages: Self-other disparities tend to grow in magnitude as the perceived social distance between self and others increases (Perloff, 2009; see also the work on the spiral of silence, e.g., Hampton et al., 20I4).

Within the scope of an SR approach, false consensus and false uniqueness can be considered to stem from different social positions reflecting the interaction between actual opinions and perceptions of other groups' opinions. Because these two positions are social in nature, they are likely to be influenced by the social and temporal contexts around the object and, in particular, its novelty in the public debate and its connection with specific political strategies. First, the novelty of the debate might lead people to lack information when picturing others' opinions. For a novel issue, perceptions of others' opinions might lag behind the changes in the actual climate of opinions. This explanation is in line with the cognitive mechanism (Mullen \& $\mathrm{Hu}$, I988; Wojcieszak, 2008; Wojcieszak \& Price, 2009). Second, political contentiousness is likely to favor the polarization of false consensus and false uniqueness. For conservatives, there is a motivation to demonstrate the normative legitimacy of one's position and a motivation to be different for liberals. This second explanation is in line with the motivational mechanism (Mullen \& $\mathrm{Hu}, \mathrm{I} 988$; 
Wojcieszak, 2008; Wojcieszak \& Price, 2009). Hence, endorsing an SR approach to study false consensus and false uniqueness provides a tool to obtain a better theoretical understanding of these effects.

Endorsing an SR approach is also meaningful from an analytical perspective. Within the SR field, a three-step analytical approach has been proposed to explore social positioning as an articulation of the points of reference and groups of individuals supporting different positions in the debate (Clémence, 200I; Elejabarrieta, I994). The first step aims to identify the shared points of reference (e.g., the perception of most people's opinions). The next step is focused on social positioning and aims to identify the association between the opinions held by participants and the shared points of reference. This step can be linked with the idea of identifying false consensus and false uniqueness. The last step addresses the characteristics of individuals and groups to identify the principles (e.g., political orientation) that organize these social positions. This analytical approach rests upon factorial analyses, such as cluster analyses, as they provide tools to classify individuals depending on their social positioning (Clémence, 200I).

In this article, we apply the SR analytical approach to study false consensus and false uniqueness. This approach, particularly the application of cluster analyses, allows for grouping individuals based on their answers. It also allows for measuring consensus and uniqueness without reducing answers to the different variables to a single indicator, as is usually done in studies of false consensus and false uniqueness (e.g., Dvir-Gvirsman, 2015; Stern et al., 2014; Strube \& Rahimi, 2006). The added value of such an approach is that different groups of reference and perceptions of their opinions can be considered along with personal opinions. Moreover, it provides tools to account for false consensus and false uniqueness among groups of respondents, particularly conservatives and liberals.

The SR analytical approach allows us to show in this article that the occurrence of pluralistic ignorance (i.e., false consensus, false uniqueness) is likely to be highly dependent on the attitude object through its novelty in the public debate and on the political strategies that it implies for conservatives and liberals. To show this influence, we compare social positioning-regarding different groups of reference-toward two attitude objects: same-sex female parenting and working mothers.

\section{Swiss Societal Background on Same-Sex Female Parenting and Working Mothers}

In the context of this study, same-sex female parenting and working mothers have several similarities that make an examination of the pluralistic ignorance phenomenon valuable. While both issues target mothers, their novelty in the 
public debate differs. This difference was documented in a March 2015 report on the modernization of family law released by the Swiss Federal Council (Swiss Federal Council, 20 I5). This report was dedicated to describing past and present family dynamics through the evolution of the role of women (e.g., increasing proportion of working mothers). It also addressed future and current legal changes through a discussion of same-sex couples' rights (e.g., the legal gap between Switzerland and several countries that opened marriage and adoption to same-sex couples). This distinction between past and future changes highlights differences in the novelty in the public debate, as much as the political strategies involved, for issues regarding working mothers and same-sex (female) parenting.

While the number of working mothers with a preschool-age child tripled between I980 and 2017 and working mothers have switched from being a minority to a majority in Switzerland (Giudici \& Schumacher, 20I7), issues around same-sex couples occupy a central position in the political sphere. Same-sex marriage and same-sex adoption (with the exception of stepchild adoption since 2018) are not legal in Switzerland. However, same-sex marriage and adoption, as well as same-sex parenting, are currently being debated in parliament. For example, a parliamentary initiative to open marriage to same-sex couples was proposed in 2013 and is still being discussed in the Swiss government. The debate and legal issues around this object-especially regarding what marriage for all would mean for same-sex adoption and parenting-led the government to extend the discussions to 2019 .

The differences in the social and temporal contexts around same-sex (female) parenting (i.e., not legally allowed, jurisdictional discussions, new debate) and working mothers (i.e., legally allowed, different laws, older debate) are likely to lead to variations in social positioning. We expect to find more occurrences of pluralistic ignorance for this "new" changing issue because a polemical new process is involved in same-sex (female) parenting (i.e., the opinion climate is not settled). Simply put, people may lack information to identify the changes in the actual opinion climate. Moreover, as same-sex (female) parenting is a more contentious issue than that of working mothers, it is more likely to lead to the activation of ego-defensive/group motivations, resulting in false consensus for conservatives and false uniqueness for liberals.

To summarize, we formulated the following hypotheses. HI: Pluralistic ignorance (i.e., a mismatch between the perceived majority/minority of others' opinions and the actual minority/majority of personal opinions) is stronger for same-sex female parenting than for working mothers. H2: Right-wing respondents (conservatives) express a stronger false consensus tomard same-sex female parenting than working mothers; left-ming respondents (liberals) express a stronger false 
uniqueness tomard same-sex female parenting than morking mothers. In this study, we also consider representations depending on groups of reference and their level of closeness to each respondent (i.e., people, neighbors, friends, and relatives). We will also explore the role of the level of closeness of the group of reference because research has documented that people perceive larger self-other disparities with general others than with close others (e.g., Hampton et al., 20I4; Perloff, 2009).

\section{Method}

\section{Participants and Procedure}

Data were collected in the canton of Vaud in Switzerland in October 20I6. The canton of Vaud is geographically organized into $3 \mathrm{I} 6$ municipalities, which are historically divided into politically progressive urban areas and politically conservative rural areas (Kübler, Scheuss, \& Rochat, 2013). To reflect these geographical cleavages, the study was based on a two-stage sampling method, ${ }^{1}$ with adult residents of municipalities within the canton of Vaud as the target population. In the first stage, 30 municipalities within three geographical categories of municipality — urban areas $\left(N_{\text {Vaud }}=53\right)$, peri-urban areas $\left(N_{\text {Vaud }}=200\right)$, and rural areas $\left(N_{\text {Vaud }}=65\right)$-were selected. Within each of these three categories, ro municipalities were randomly selected. Within each municipality, a minimum of two postal addresses were randomly selected as starting points. During the second stage, residents of the 30 municipalities were randomly selected using the random-route method. A questionnaire was delivered to each selected household, and a maximum of io residents per building were contacted. In each municipality, 8o self-administered paperbased questionnaires $(N=2,400)$ and 40 contact letters with a link to a web survey $(N=\mathrm{I}, 200)$ were distributed.

Of the 3,60o contacted people, 89I $(37 \cdot 3 \%)$ returned the paper-based questionnaire, and $2 \mathrm{I} 3(\mathrm{I} 7.8 \%)$ responded to the web version of the questionnaire. Due to missing cases ("do not know" answers or nonresponses mainly pertaining to questions about other people's opinions), 36I participants were excluded a priori. The final sample included 743 residents $(320$ men, 42 I women, two unspecified; $M_{\text {age }}=5 \mathrm{I} .74$ years, $S D=\mathrm{I} 5.8 \mathrm{I} ; 26.6 \%$ with a university degree). ${ }^{2}$

\footnotetext{
${ }^{1}$ The initial goal was to conduct a multilevel analysis to reflect differences among municipalities. The low intraclass correlation $(<.02)$ led us to ignore the hierarchical structure of the data.

${ }^{2}$ In comparison to the population of the canton of Vaud in $20{ }_{5}$ (STATVD, 20I6), our sample is slightly older (mean age in the canton of 47.7 years old), feminized (51.5\% of the population is women), and educated (2I.4\% have a university degree).
} 


\section{Variables}

Political orientation. Liberal-conservative orientation was measured with the question, "On political issues, when people talk about right and left, where would you place yourself?" The response scale was $\mathrm{I}=$ far left, $2=$ left-ming, $3=$ center-left, $4=$ center, $5=$ center-right, $6=$ right-ming, and $7=$ far right $(M=4$. Iо,$S D=$ I.1 8$)$.

Personal opinion and perceived opinions toward same-sex female parenting. ${ }^{3}$ Personal opinion toward same-sex female parenting was measured with a single item: "To what extent do you approve or disapprove of a samesex female couple bringing up a child?" The response scale ranged from $\mathrm{I}=$ strongly disapprove to $5=$ strongly approve $(M=3.00, S D=\mathrm{I} .40)$.

Perceived opinions toward same-sex female parenting were measured by asking each respondent: "How do you think most people $(M=2.06, S D=$ $0.8 \mathrm{I})[/$ most of your neighbors $(M=2.24, S D=0.92)][/$ most of your friends and relatives $(M=2.5 \mathrm{I}, S D=\mathrm{I} .32)]$ would react to a same-sex female couple bringing up a child?". ${ }^{4}$ These items were adapted from the validated and pretested European Social Survey (2006) items measuring perceived opinions. Each time, the response scale was $\mathrm{I}=$ mould openly disapprove, $2=$ mould disapprove without saying it, $3=$ would not mind either way, $4=$ would approve without saying it, and $5=$ mould openly approve. An additional "I don't know" response, excluded from the analyses, was offered to the respondents.

Personal opinion and perceived opinions toward working mothers. Personal opinion toward working mothers was measured by asking each respondent, "To what extent do you approve or disapprove of a woman having a full-time job while she has a child aged under 3 ?" $(M=3.04, S D=1.25)$. Perceived opinions toward working mothers were measured by asking each respondent, "How do you think most people $(M=2.59, S D=0.92)[/$ most of your neighbors $(M=2.7 \mathrm{I}, S D=0.98)][/$ most of your friends and relatives $(M=2.72, S D=\mathrm{I} .36)]$ would react if a woman has full-time job while she has a child aged under 3?" (also adapted from the European Social Survey, 2006). The response categories for all the items were the same as those for same-sex female parenting.

Control variables. Participant sex $(\mathrm{I}=$ female, 56.8\%), age (in years, $\left.M=5_{5} \mathrm{.} .74, S D=\mathrm{I}_{5} .8 \mathrm{I}\right)$, university degree ( $\mathrm{I}=$ having a university degree, $26.6 \%$ ), level of religiosity (from $\mathrm{I}=$ not at all religious to $5=$ completely religious; $M=2.89, S D=\mathrm{I} .39$ ), and geographic type of municipality of residence ( $\mathrm{I}=$ rural municipality, $32.5 \%$ ) were included in the analyses.

\footnotetext{
${ }^{3}$ We also measured opinions toward same-sex male parenting and same-sex marriage. To simplify the comparison, these measures were not included in this article.

${ }^{4}$ Respondents also had to answer for residents of the canton of Vaud. As the answers were almost the same as those for "most people," this item was not included in the analyses.
} 


\section{Results}

All the analyses presented below were conducted with $\mathrm{R}$ software (version $3 \cdot 3 \cdot 2) .^{5}$

\section{Differences in Pluralistic Ignorance}

To test for pluralistic ignorance by comparing majority/minority perceptions of others' opinions with majority/minority actual personal opinions (HI), we computed a percentage of disapproval score for personal opinions and the mean percentage of respondents who perceived that others (people, neighbors, friends, and relatives) disapproved. This procedure enabled us to directly compare majority/minority perspectives, as is commonly done in studies of pluralistic ignorance (e.g., Fields \& Schuman, I976). It also enabled us to standardize the differences in terms of response categories for personal and perceived opinions.

To compare same-sex female parenting and working mothers, we first conducted two-sample $t$-tests comparing percentages of disapproval (or perceived disapproval) for the two objects. Then, one-sample $t$-tests were conducted to test, on one hand, whether a majority (more than $50 \%$ ) or a minority (less than $50 \%$ ) of respondents disapproved and, on the other hand, whether a majority or a minority of respondents perceived that the majority of others (most people, most neighbors, most friends, and relatives) disapproved.

First, as shown in Table $\mathrm{I}$, the percentages of actual disapproval did not significantly differ between same-sex parenting and working mothers, $t(742)$ $<\mathrm{I}, p=.66 \mathrm{o}$. A minority of respondents $(38.4 \%)$ disapproved of same-sex female parenting, and a minority of respondents $(37.4 \%)$ also disapproved of working mothers. Second, the percentages of perceived most people's disapproval differed between same-sex female parenting and working mothers, $t(742)=\mathrm{I} 2.07, p<.00 \mathrm{I}, \eta_{\mathrm{p}}^{2}=. \mathrm{I} 6$. A majority of respondents $(77.7 \%)$ perceived that most people would disapprove of same-sex female parenting,

\footnotetext{
${ }^{5}$ The analyses were conducted on the reduced dataset. To control for the robustness of our results, we imputed nonresponses using a multiple imputation procedure (Io imputed datasets). We do not report the results based on the imputed dataset in the text due to clarity issues and limitations to pool the results of complex analyses. The results between the imputed and restricted dataset were similar: a minority of respondents $(38.2 \%)$ disapproved of same-sex female parenting (disapproval significantly below $50 \%$, $t(828)=-6.97, p<.001)$, and a minority of respondents $(37.7 \%)$ disapproved of working mothers (significantly below $50 \%, t(828)=-7.33, p<.001)$. A majority of respondents $(78.6 \%)$ perceived that most people would disapprove of same-sex female parenting (significantly above $50 \%, t(828)=20 . \mathrm{I} 5, p<.00 \mathrm{I}$ ), and respondents $(\mathbf{5 2} .8 \%)$ were not a majority in perceiving that most people would disapprove of working mothers (not significantly above $50 \%, t(828)=\mathrm{I} .60, p=.060$ ). There was a significant three-way interaction among the object, the group of reference, and political orientation, $F(3,248 \mathrm{I})=\mathrm{I} 7.64, p<$. .oor, $\eta_{\mathrm{p}}{ }^{2}$ $=.02$. Political orientation was a strong predictor of the probability of being in the FC cluster, OR $=\mathrm{I} \cdot 5^{2}$, $95 \%$ CI [I.3І, г.76], $p<.00$ I.
} 
Table I

Percentage of Disapproval Using One-Sided t-Tests for Comparison with 50\%

Item

Disapproval (\%) $90 \%$ CI One-sided $t$-test

Same-sex female parenting

Personal opinion

Most people's opinion

38.4

$77 \cdot 7$

Most neighbors' opinion

$69 \cdot 3$

Most friends' and relatives' opinion

Working mothers

Personal opinion

Most people's opinion

58.8

Most neighbors' opinion

Most friends' and relatives' opinion

$37 \cdot 4$

52.0

$45 \cdot 5$

$5^{\mathrm{I}} \cdot 5$

$\begin{array}{ll}{[34.9,4 \mathrm{I} .9]} & -6.52^{* * *} \\ {[74.7,80.7]} & \text { I } 8.09^{* * *} \\ {[66.0,72.6]} & \text { I I.4I*** } \\ {[55.3,62.4]} & 4.88^{* * *} \\ & \\ {[33.9,40.9]} & -7.08^{* * *} \\ {[48.4,55.6]} & \text { I.06 } \\ {[4 \mathrm{I} .9,49 . \mathrm{I}]} & -2.47^{* *} \\ {[47.9,55 . \mathrm{I}]} & <\mathrm{I}\end{array}$

Note. CI = confidence interval.

$* * * *_{p}<$.OOI, one-tailed. ${ }^{* *} p<$. oI, one-tailed.

and neither a majority nor a minority of respondents $(52.0 \%)$ perceived that most people would disapprove of working mothers. Third, the percentages of perceived most neighbors' disapproval differed between same-sex female parenting and working mothers, $t(742)=\mathrm{I} \mathrm{I}_{3} 30, p<.00 \mathrm{I}, \eta_{\mathrm{p}}{ }^{2}=. \mathrm{I}_{5}$. A majority of respondents $(69.3 \%)$ perceived that most of their neighbors would disapprove of same-sex female parenting, and a minority of respondents $(45 \cdot 5 \%)$ perceived that most of their neighbors would disapprove of working mothers. Finally, the percentages of perceived disapproval among most friends and relatives differed between same-sex female parenting and working mothers, $t(742)=3.48, p=.00 \mathrm{I}, \eta_{\mathrm{p}}{ }^{2}=.02$. A majority of respondents $(58.8 \%)$ perceived that most of their friends and relatives would disapprove of samesex female parenting, and neither a majority nor a minority $(5 \mathrm{I} .5 \%)$ perceived that most of their neighbors would disapprove of working mothers. In sum, consistent with our first hypothesis, we observed that although both objects were associated with the same level of disapproval, pluralistic ignorance was found for same-sex female parenting only.

Finally, to explore the role of the level of closeness of the group of reference on self-other disparities, we conducted a two-way analysis of variance (ANOVA) on the percentage scores with the group of reference and the object as within-participant variables. We observed a significant two-way interaction between the group of reference and the object, $F(3,2226)=5_{\text {I.2 }}$, $p<$. .oor, $\eta_{\mathrm{p}}{ }^{2}=.06$. In particular, the effect of the group of reference was stronger for same-sex female parenting, $F(3,2226)=\mathrm{I}_{5} \mathrm{I} .82, p<.00 \mathrm{I}, \eta_{\mathrm{p}}{ }^{2}=. \mathrm{I} 7$, than for working mothers, $F(3,2226)=2 \mathrm{I} .33, p<.00 \mathrm{I}, \eta_{\mathrm{p}}{ }^{2}=.03$. In the case of same-sex female parenting, personal opinions $(38.4 \%)$ were more distant from the opinion of general others (i.e., most people, $77.7 \%$ disapproval) than from 
the opinion of close others (i.e., most friends and relatives, $58.8 \%$ disapproval). This finding suggests that for this object, self-other disparities increased as the level of closeness decreased.

\section{Consensus and Uniqueness Among Different Political Orientations}

In the previous section, we documented evidence of pluralistic ignorance for same-sex female parenting and, hence, a false social knowledge of other people. However, no evidence of pluralistic ignorance for working mothers was found. With the following analyses, we further investigated the nature of this false knowledge by testing for differences in expressions of false consensus and false uniqueness among conservatives and liberals $\left(\mathrm{H}_{2}\right)$.

Interaction between objects, group of reference, and political orientation. To see whether differences among political orientation for the two objects were likely to be found, we conducted three-way mixed measures ANOVA with the group of reference and the object as within-participant variables and political orientation (7-point scale) as a between-participant continuous variable.

The visual representation of mean differences among political orientation is displayed in Figure I. The results of the three-way ANOVA revealed a significant three-way interaction between the object, the group of reference, and political orientation, $F(3,2223)=17.03, p<.001, \eta_{\mathrm{p}}{ }^{2}=.02$. The interaction between the level of reference and political orientation was stronger for same-sex female parenting, $F(3,2223)=57.5 \mathrm{I}, p<.00 \mathrm{I}, \eta_{\mathrm{p}}{ }^{2}=.07$, than for working mothers, $F(3,2223)=9.45, p<.00 \mathrm{I}, \eta_{\mathrm{p}}{ }^{2}=$. or. In the specific case of same-sex female parenting, the analyses revealed that the effect of the group of reference was stronger for liberal respondents $(-\mathrm{I} S D), F(3,2223)=2 \mathrm{I} 0.47$, $p<.00 \mathrm{I}, \eta_{\mathrm{p}}{ }^{2}=.22$ (corresponding to a stronger differentiation between personal and other opinions, i.e., false uniqueness) than for conservative respondents $(+\mathrm{I} S D), F(3,2223)=\mathrm{I} 7.9, p<.00 \mathrm{I}, \eta_{\mathrm{p}}{ }^{2}=.02$ (corresponding to a weaker differentiation between personal and other opinions, i.e., false consensus). In the specific case of working mothers, the analyses revealed that the effect of the group of reference was weak for both liberal respondents, $F(3,2223)=37.8 \mathrm{I}, p<.00 \mathrm{I}, \eta_{\mathrm{p}}{ }^{2}=.05$ and conservative respondents, $F(3,2223)=10.26, p<.00 \mathrm{I}, \eta_{\mathrm{p}}^{2}=.0 \mathrm{I}$.

These results show that the effect of political orientation differs between same-sex female parenting and working mothers. The effects of political orientation on personal opinions and perceived others' opinions were stronger for same-sex female parenting than for working mothers. These analyses also showed that, in the case of same-sex female parenting, liberal respondents differentiated more between their personal opinion and those of others.

To directly test for false consensus and uniqueness and, in particular, to see whether these two social positions really structure answers at a theoretical 
Figure I

Relationship between political orientation and approval scores for same-sex female parenting (a) and working mothers (b)

(a)

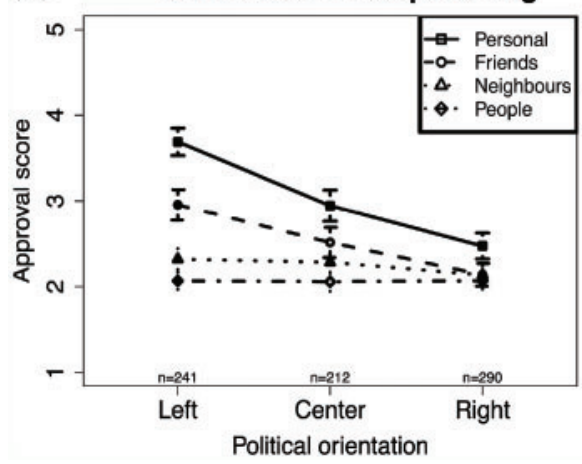

(b)

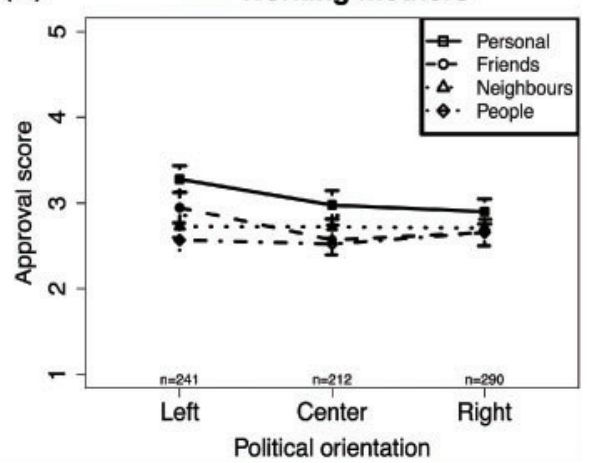

Note. Error bars represent $95 \%$ CI. CI $=$ confidence interval

level, we conducted cluster analyses by focusing on same-sex female parenting (the more-debated object) only. Such an approach, based on SR, allowed for controlling the existence of false consensus and false uniqueness without inferring or creating a priori categories. It allowed us to directly test for the effect of political orientation on these social positions and comprised a more comprehensive and robust analysis.

Cluster analyses, false consensus, and false uniqueness. To compare different cluster solutions and assess the reliability of our results, hierarchical agglomerative cluster analyses were conducted on the four items for same-sex female parenting. This procedure allowed us to compare different cluster solutions (e.g., varying the number of clusters), as there is a hierarchy between the clusters (Hair, Black, Babin, \& Anderson, 20го). The hierarchical cluster analysis was performed using Ward's method and the Euclidean distance metric. We first identified the possible best number of clusters using the NbClust package (Charrad, Ghazzali, Boiteau, \& Niknafs, 20I4) and then reported the cluster solutions.

Based on the methods encoded in the $\mathrm{R}$ package NbClust (Charrad et al., 20I4), a two-cluster analysis was conducted. These two clusters classified respondents based on their personal opinion and on their perceptions of others' opinions. Cluster I gathered 422 respondents who held a positive personal opinion $(M=3.86)$, similar to their friends and relatives $(M=3.28)$ but different from their neighbors $(M=2.64)$ and most people $(M=2.25)$. Hence, this cluster could be named the false uniqueness (FU) cluster. In contrast, Cluster 2 gathered $32 \mathrm{I}$ respondents with a negative personal opinion $(M=\mathrm{r} .87)$ who, in the same way, perceived that most of their friends and 
relatives $(M=\mathrm{I} .50)$, their neighbors $(M=\mathrm{I} .70)$, and most people $(M=\mathrm{I} .82)$ held negative opinions. This cluster grouped people who did not differentiate between their personal opinion and others' opinions and could be consequently named the false consensus (FC) cluster.

Because pluralistic ignorance was less documented for working mothers, the positions should differ less on the basis of consensus and uniqueness. To control for this expectation, we conducted a cluster analysis for working mothers. As expected, the analysis was much less conclusive for working mothers than for same-sex female parenting. A large majority of respondents $(74.3 \%)$ were grouped in a cluster in which perceptions and opinions only differed to a small extent (see Supplementary Materials Annex SA for additional analyses on working mothers).

Logistic regression to explain false consensus and false uniqueness. From the results of the cluster analysis, a variable that assigned one cluster to each respondent was created. To test the second hypothesis, a binomial logistic regression was conducted to predict the probability of being in the FC cluster instead of the FU cluster. The focal independent variable was political orientation and the control variables were sex, age, university degree, level of religiosity, and type of municipality of residence (see Table 2).

Confirming our second hypothesis, political orientation was a strong predictor of the probability of being in the FC cluster, odds ratio $(O R)=\mathrm{I} .5^{\circ}$, $95 \%$ confidence interval (CI) [I.30, I.73], $p<.00$ I. Level of religiosity was also a strong predictor of being in the FC cluster $(O R=\mathrm{I} .3 \mathrm{I}, 95 \%$ CI [ [. I6, I.48], $p<.00 \mathrm{I})$, and male respondents were I.7 times more likely to be in the FC cluster $(O R=\mathrm{I} .72,95 \%$ CI $[\mathrm{I} .24,2.39], p=.00 \mathrm{I})$. The analyses were also conducted on the clusters for working mothers, and no significant effect of political orientation was found (see Supplementary Annex SB). This finding

Table 2

Logistic Regression Analyzing Likelihood of Being in the False Consensus Cluster Tomard Same-Sex Female Parenting

\begin{tabular}{|c|c|c|}
\hline & Odds ratio & $95 \% \mathrm{CI}$ \\
\hline Intercept & $0.04^{* * *}$ & {$[0.02,0.10]$} \\
\hline Sex (male) & $\mathrm{I} .72^{* *}$ & {$[1.24,2.39]$} \\
\hline Age & I.OI & {$[1.00,1.02]$} \\
\hline Level of education (university degree) & 0.83 & {$[0.57,1.20]$} \\
\hline Level of religiosity & $\mathrm{I} \cdot 3 \mathrm{I}^{* * *}$ & {$[$ I. 16, I.48] } \\
\hline Geographic category (rural) & 0.94 & {$[0.67,1.32]$} \\
\hline Political orientation & I. $50^{* * *}$ & {$[\mathrm{I} .30,1.73]$} \\
\hline
\end{tabular}

Note. CI = confidence interval.

$* * *{ }_{p}<$. оо I, $n=706$, Nagelkerke $R^{2}=.139$, Accuracy $=62.9 \%$ 
indicates that political orientation strongly influenced false consensus and false uniqueness for same-sex female parenting only.

\section{Discussion}

This research is the first to formally work on attitude objects by examining differences between personal opinions and perceived opinions toward same-sex female parenting (current debated object) and working mothers (older debated object). Furthermore, we proposed a new way of conceptualizing pluralistic ignorance (false consensus and false uniqueness) among conservatives and liberals through the endorsement of an SR approach to explore the processes by which people categorize themselves through social positioning (Elcheroth et al., 20I I; Moscovici, I99I). The results discussed below indicate that (a) there is evidence that pluralistic ignorance occurs for same-sex female parenting and that this phenomenon might be due to the issue's novelty in the public debate (i.e., settled or unsettled issue) and (b) pluralistic ignorance arises from false consensus among conservatives and from false uniqueness among liberals.

First, by showing that pluralistic ignorance was documented for opinions toward same-sex female parenting (for all groups of reference) and not for working mothers, we illustrated that the social and temporal contexts around the object influence pluralistic ignorance. In line with our first hypothesis (HI), we showed that a majority of respondents did not disapprove of same-sex female parenting, while a majority of these respondents perceived that most people/their neighbors/their friends and relatives disapproved. On the other hand, this effect was not documented for working mothers, as a majority did not perceive that most people/their neighbors/their friends and relatives disapproved. Moreover, we showed that in a situation of pluralistic ignorance, the distance between personal opinions and perceptions of others' opinions was greater for more distant groups of reference. On the whole, our findings might indicate that less debated and/or older objects, for which the opinion climate is more settled, lead to less evidence of pluralistic ignorance.

Second, our analyses on social positioning toward same-sex female parenting reveal that false consensus and false uniqueness explain pluralistic ignorance. In line with the second hypothesis $\left(\mathrm{H}_{2}\right)$, our results show that conservative (right-wing) respondents almost never differentiate between their personal opinion and their perception of others' opinions. However, liberal (left-wing) respondents differentiate a great deal between their personal opinion and their perception of others' opinions. These results corroborate previous findings in the literature on false consensus (e.g., Amit et al., 2010; Dvir-Gvirsman, 2015) and false uniqueness (e.g., Rabinowitz et al., 2016; Stern et al., 20I4). Furthermore, the comparison between opinions toward same-sex female parenting and working mothers might also indicate that 
these effects are more likely to be found for newly debated objects that involve political strategies for the future.

Beyond these findings, our research does not provide clear evidence to distinguish the effects of the novelty of the debate (cognitive mechanism) from the effects of the political strategies (motivational mechanism) around the objects. To disentangle the effects of novelty and political strategies on false consensus and false uniqueness, future research should consider adding a measure of the perceived level of novelty of the debate and a measure of political interest in the debate. Although the design of our study did not provide us with tools to disentangle the effects, it is likely that both effects influence pluralistic ignorance. Below, we discuss this question by expanding the novelty of the debate to the idea of a time lag and expanding the level of controversy to the idea of group conflicts.

\section{Do Perceptions of Others' Opinions Lag Behind Opinions for New Debates?}

Our first suggestion is that the evidence of pluralistic ignorance documented in this study might come from the novelty of the debate around same-sex female parenting. Perceptions of most people's opinion toward same-sex female parenting are very homogenous and negative. Indeed, even though opinions vary, the perception of most people's opinions reflects a stable conservative representation of most people's opinions. Thus, these results show the dynamic nature of representations. Some representations, especially when they are shared, serve as a framework for the interpretation of new objects (Sammut, Tsirogianni, \& Wagoner, 20I2). Within the SR approach, stable and uniform representations are defined as hegemonic. Such representations are so widely shared between the groups that they are implicit and often reified through institutions (Moscovici, I988). However, such hegemonic representations also ensure a form of primacy of the past over the present (Moscovici, 2000), suggesting the presence of a time lag. This idea of a time lag might be an explanation, arising from a cognitive mechanism, for our results. We find that opinions are polarized, but our results suggest that individuals do not actualize their representations and still perceive others' opinions as being conservative.

Our observations are in accordance with studies on pluralistic ignorance (e.g., Fields \& Schuman, I976; O'Gorman, I988; Zou et al., 2009) that showed that "a society's perception of itself tends to lag behind actual change in people's private beliefs and values" (Zou et al., 2009, p. 58I). Furthermore, these findings have also been documented in new research on norms (Tankard \& Paluck, 20I6, 20I7) that explained the stability of the perceptions by the fact that in times of social change, people may fail to identify ongoing changes in opinions due to a lack of information. In the 
scope of our study, we could imagine that the institution's position toward same-sex couples is an important source of information to perceive others' opinions, especially in Switzerland. Future research should examine the evolution of perceptions and opinions across time or in an experimental setting.

\section{Why Are Representations of Debated Objects So Stable?}

The non-actualization of representations documented here may also be accounted for by variables other than the temporal context. Group status and conflict between groups might serve as additional explanations arising from a motivational mechanism. Through the investigation of false consensus and false uniqueness, we found that for same-sex female parenting, being male, religious, and holding a right-wing political orientation are strong predictors of the probability of being in the false consensus cluster. These groups have historical specificities that may explain their presence in this cluster. Historically, the native Swiss, the right, religious people, and males have been dominant in the political system (Kriesi \& Trechsel, 2008). Hence, one can understand this presence of dominant groups that hold political power in the false consensus cluster through the idea of the influence of group status on representations. Indeed, SRs also have a historical dimension, and they endorse the "power of the groups that embody the values that underpin them" (Joffe \& Staerklé, 2007, p. I43). Therefore, the stability of negative hegemonic representations might also be accounted for by the fact that dominant groups endorse them (Staerklé, Clémence, \& Spini, 20 I I).

\section{Limitations and Concluding Remarks}

There are some limitations to the data and analyses that warrant discussion. First, the comparison between same-sex female parenting and working mothers might be limited, as we did not experimentally test for the effects of debate or novelty on pluralistic ignorance. For this reason, we limited the comparison to their legal frame of reference and their novelty in the public debate. However, our results still indicate that pluralistic ignorance, false consensus, and false uniqueness vary among objects. Moreover, the novelty of the debate in addition to the political strategies involved with controversial debates seem to account for these differences. Ideally, one should study the evolution of social positioning across time for the same object.

Another limitation is related to the measures of perceived opinions, which differ slightly from the measures of personal opinions. We decided to have different measures of opinions for two main reasons. First, to enhance the comparison while also using reliable and valid items, we used the measures of perceived opinions proposed in the third round of the European Social Survey (2006). Second, the response categories were chosen to facilitate respondents' 
cognitive process and, in particular, to allow us to access their "true" perception of others' opinions. Measures that do not include expression are difficult to interpret because one cannot differentiate between an opinion's expression and actual opinions (e.g., a respondent may believe that other people would approve, given their expressions, and at the same time believe that they privately disapprove). We account for the fact that, although this formulation further illuminates the phenomenon of consensus and uniqueness, the difference between the two measures might affect evidence of pluralistic ignorance. Consequently, we standardized the data for the analyses of pluralistic ignorance by comparing percentages of disapproval instead of the mean differences, which allowed us to directly access majority/minority opinions.

A final limitation is related to the social desirability bias. This bias arises when participants are asked questions about socially sensitive issues (Glynn, I989), such as homosexuality (e.g., Tourangeau \& Yan, 2007). In these situations, people are unwilling to report their "true" opinions, but they may project them when reporting their perceptions of others' opinions (Glynn, I989). To minimize this bias, the questionnaire was presented as a study on different family forms, and the topic of homosexuality was not salient because only a few items touched on it. Moreover, the questionnaire was anonymous and self-administered.

Despite the limitations mentioned above, we believe our findings have normative and policy-making implications. In this specific normative window of time (i.e., social change toward more equality; Crandall \& Warner, 2005), the perception that others hold negative opinions toward same-sex (female) parenting might serve as an argument for both conservatives and liberals to maintain or change the legal situation. Conservatives might argue against legal changes toward greater recognition of same-sex parenting based on the perceived consensus around their opinion within the population. For liberals, the picture is less straightforward. On the one hand, based on the perceived uniqueness of their opinion, liberals might strategically argue that it is better to retain the law until opinions in the population shift toward a greater acceptance of same-sex parenting. On the other hand, perceptions of positive opinions among their friends and relatives might motivate them to act for legal change. Thus, political parties and policy makers aiming to convince liberals to act for legal change may have to take liberals' feelings of uniqueness into account, trying to adjust their misperceptions of others' opinions.

To summarize, our method based on social positioning provided an effective way to congruently study false consensus and false uniqueness by integrating as many variables and groups of reference as needed. We showed that perceptions are not always accurate mirrors of personal opinions, particularly when the object is new and/or debated in the political sphere. 


\section{Supplementary Data}

Supplementary Data are available at IFPOR online.

\section{Acknowledgements}

This publication was partially funded by the Swiss National Centre of Competence in Research LIVES-Overcoming vulnerability: Life course perspectives (NCCR LIVES), which is financed by the Swiss National Science Foundation.

\section{References}

Amit, A., Roccas, S., \& Meidan, M. (2010). A group just like me: The moderating role of conservation values on social projection. European Journal of Social Psychology, 40, 93 I-945. doi: го. I002/ejsp. 658

Babad, E., \& Yacobos, E. (I993). Wish and reality in voters' predictions of election outcomes. Political Psychology, I4, 37-54. doi:10.2307/3791392

Bosveld, W., Koomen, W., van der Pligt, J., \& Plaisier, J. W. (1995). Differential construal as an explanation for false consensus and false uniqueness effects. Fournal of Experimental Social Psychology, 3I, 518-532. doi:10.10o6/ jesp. I995. I023

Bowen, A. M., \& Bourgeois, M. J. (200I). Attitudes toward lesbian, gay, and bisexual college students: The contribution of pluralistic ignorance, dynamic social impact, and contact theories. Fournal of the American College Health Association, 50, 9I-96. doi: Io. I080/074484801095960I2

Charrad, M., Ghazzali, N., Boiteau, V. and Niknafs, A. (20I4). NbClust package: finding the relevant number of clusters in a dataset. Fournal of Statistical Softmare, 6I, I-36. doi: Io. I8637/jss.vo6r.io6

Clémence, A. (200I). Social positioning and social representations. In K. Deaux, \& G. Philogène (Eds.), Representations of the social: Bridging theoretical traditions (pp. 83-95). Oxford: Blackwell Publishers.

Cohen, L. L., \& Shotland, R. L. (1996). Timing of first sexual intercourse in a relationship: Expectations, experiences, and perceptions of others. Fournal of Sex Research, 33, 29I-299. doi:I0.1080/0022449960955I846

Crandall, C. S., \& Warner, R. H. (2005). How a prejudice is recognized. Psychological Inquiry, I6, I37-I4I. doi:2005-09295-0I2

Dvir-Gvirsman, S. (2015). Size matters: The effects of political orientation, majority status, and majority size on misperceptions of public opinion. Public Opinion Quarterly, 79(I), I-27. doi:Io.I093/poq/nfuo6I

Elcheroth, G., Doise, W., \& Reicher, S. (20II). On the knowledge of politics and the politics of knowledge: How a social representations approach helps us rethink the subject of political psychology. Political Psychology, 32, 729-758. doi:Io.IIII/ j. I $467-922$ I.20 I I.00834.X 
Elejabarrieta, F. (I994). Social positioning: a way to link social identity and social representations. Social Science Information, 33, 24I-253. doi:Io.II77/ 053901894033002006

European Social Survey (20I6). ESS round 8 source questionnaire. London: ESS ERIC Headquarters c/o City University London. Retrived from https://www.europeansocialsurvey.org/docs/round8/fieldwork/source/ESS8_source_questionnaires.pdf

Eveland, W. P., \& Glynn, C. J. (2008). Theories on the perception of social reality. In W. Donsbach, \& M. W. Traugott (Eds.), The SAGE handbook of public opinion research (pp. I55-163). London: SAGE Publications Ltd.

Fields, J. M., \& Schuman, H. (1976). Public beliefs about the beliefs of the public. Public Opinion Quarterly, 40, 427-448. doi:Io.1086/268330

Giudici, F., \& Schumacher, R. (2017). Le travail des mères en Suisse: évolution et déterminants individuels. Social Change in Smitzerland, ro. doi:10.22019/SC-201700005

Glynn, C. J. (I989). Perceptions of others' opinions as a component of public opinion. Social Science Research, I8, 53-69. doi:ı.гол6/oo49-o89X(89)90003-3

Gross, S. R., \& Miller, N. (I997). The "golden section" and bias in perceptions of social consensus. Personality and Social Psychology Reviem, I, 24I-27I. doi:Io.I207/ S I 5327957psproio3_4

Hair, J. F., Black, W. C., Babin, B. J., \& Anderson, R. E. (20ıо). Multivariate data analysis. A global perspective. Boston: Upper Saddle River.

Hampton, K. N., Rainie, H., Lu, W., Dwyer, M., Shin, I., \& Purcell, K. (20I4). Social media and the 'spiral of silence'. PewResearchCenter. Retrieved from http:// www.pewinternet.org/2014/o8/26/social-media-and-the-spiral-of-silence/

Joffe, H., \& Staerklé, C. (2007). The centrality of the self-control ethos in western aspersions regarding outgroups: A social representational approach to stereotype content. Culture and Psychology, I3, 395-4I8. doi:Io. I I77/I354067Xo7082750

Katz, D., \& Allport, F. H. (I93I). Students' attitudes. Syracuse, NY: Craftman.

Kriesi, H., \& Trechsel, A. H. (2008). The politics of Smitzerland: Continuity and change in a consensus democracy. Cambridge, UK: Cambridge University Press.

Kübler, D., Scheuss, U., \& Rochat, P. (2013). The metropolitan bases of political cleavage in Switzerland. In J. M. Sellers, D. Kübler, M. Walter-Rogg, \& R. A. Walks (Eds.), The political ecology of the metropolis: Metropolitan sources of electoral behaviour in eleven countries (pp. I99-226). Colchester: ECPR Press.

Marks, G., \& Miller, N. (I987). Ten years of research on the false-consensus effect: An empirical and theoretical review. Psychological Bulletin, I02, 72-90. doi: I0.1037/0033-2909.102.1.72

Merton, R. K. (1968). Social theory and social structure. New York: Free Press.

Miller, D. T., \& McFarland, C. (I987). Pluralistic ignorance: When similarity is interpreted as dissimilarity. Fournal of Personality and Social Psychology, 53, 298305. doi: Io. I037/0022-35I4·53.2.298

Moscovici, S. (I976). La psychanalyse, son image, son public [Psychoanalysis, its image and its public] (2nd ed.) Paris: Presses Universitaires de France.

Moscovici, S. (I988). Notes towards a description of social representations. European Fournal of Social Psychology, I8, 2 I I-250. doi: Io.1002/ejsp.2420180303 
Moscovici, S. (I99I). Silent majorities and loud minorities. Annals of the International Communication Association, I4, 298-308. doi:10.1080/23808985.1991.1 1678792

Moscovici, S. (2000). The phenomenon of social representations. In G. Duveen (Ed.), Social representations: explorations in social psychology (pp. I8-77). Cambridge: Polity.

Mullen, B., \& Hu, L. T. (i988). Social projection as a function of cognitive mechanisms: Two meta-analytic integrations. British fournal of Social Psychology, 27, 333-356. doi:Io. I I I /j.2044-8309. I988.tboo836

Noelle-Neumann, E., \& Peterson, T. (2004). The spiral of silence and the social nature of man. In L. L. Kaid (Ed.), Political communication research (pp. 339356). Mahwah, NJ: Laurence Erlbaum Associates.

Noelle-Neumann, E. (I993). The spiral of silence: Public opinionour social skin, 2nd ed., Chicago: University of Chicago Press.

O'Gorman, H. J. (I988). Pluralistic ignorance and reference groups: The case of in-group ignorance. In H. J. O'Gorman (Ed.), Surveying social life: paper in honor of Herbert H. Hyman (pp. I45-I73). Middletown, CT: Wesleyan University Press.

Perloff, R. M. (2009). Mass media, social perception, and the third-person effect. In J. Bryant \& M. B. Oliver (Eds.). Media effects: Advances in theory and research (pp. 252-268). New York: Routledge.

Prentice, D. A., \& Miller, D. T. (I993). Pluralistic ignorance and alcohol use on campus: some consequences of misperceiving the social norm. Fournal of Personality and Social Psychology, 64, 243. doi:10.1037/oo22-35I4.64.2.243

Rabinowitz, M., Latella, L., Stern, C., \& Jost, J. T. (20г6). Beliefs about childhood vaccination in the United States: Political ideology, false consensus, and the illusion of uniqueness. PLoS One, II, eoI58382. doi:Io.I37I/journal.pone.or 58382

Reid, S. A., \& Hogg, M. A. (2005). A self-categorization explanation for the third-person effect. Human Communication Research, 3I, I29-I6I. doi:Io. I093/hcr/3 I.I.I 29

Ross, L., Greene, D., \& House, P. (r977). The “false consensus effect”: An egocentric bias in social perception and attribution processes. Fournal of Experimental Social Psychology, I3, 279-30г. doi:ı.гіог6/o022-го3і(77)90049-X

Sammut, G., Andreouli, E., Gaskell, G., \& Valsiner, J. (20I5). The Cambridge handbook of social representations. Cambridge: Cambridge University Press.

Sammut, G., Tsirogianni, S., \& Wagoner, B. (2012). Representations from the past: Social relations and the devolution of Social Representations. Integrative Psychological and Behavioral Science, 46, 493-5I I. doi:Io.roo7/si2 I24-0і2-92 I2-0

Staerklé, C., Clémence, A., \& Spini, D. (20г I). Social representations: A normative and dynamic intergroup approach. Political Psychology, 32, 759-768. doi:Io.iıi / j.I $467-922$ I.20I I.00839.x

Statistique Vaud [STATVD] (20I6), Population résidante permanente par âge exact, sexe et origine, Vaud I980-20I6 [Data file]. Retrieved from http://www.pisepub.vd.ch

Stern, C., West, T. V, \& Schmitt, P. G. (2014). The liberal illusion of uniqueness. Psychological Science, 25, I37-144. doi: го. I 177/09567976г3500796

Strube, M. J., \& Rahimi, A. M. (2006). "Everybody knows it's true": Social dominance orientation and right-wing authoritarianism moderate false consensus for stereotypic beliefs. Fournal of Research in Personality, 40, I038-1053. doi:Io. гог6/j.jrp.2005. I0.004 
Swiss Federal Council. (2015). Rapport du Conseil Fédéral: Modernisation du droit de la famille [Data file]. Retrieved from https://www.ejpd.admin.ch/ejpd/fr/home/ aktuell/news/20 I 5/20 I 5-03-250.html

Tankard, M. E., \& Paluck, E. L. (20I6). Norm perception as a vehicle for social change. Social Issues and Policy Reviem, IO, I8I-2I I. doi:Io. I I I/sipr. I2022

Tankard, M. E., \& Paluck, E. L. (20I7). The effect of a Supreme Court decision regarding gay marriage on social norms and personal attitudes. Psychological Science, 28, I334-I344. doi:Io. I I77/09567976I7709594

Tourangeau, R., \& Yan, T. (2007). Sensitive questions in surveys. Psychological Bulletin, I33, 859-883. doi:I0.I037/oo33-2909.I33.5.859

Wagner, W. (I995). Social representations, group affiliation, and projection: knowing the limits of validity. European Fournal of Social Psychology, 25, I25-139. doi: Io.1002/ejsp.2420250202

Wojcieszak, M. (2008). False consensus goes online: Impact of ideologically homogeneous groups on false consensus. Public Opinion Quarterly, 72, 78I-79I. doi: Io. $1093 / \mathrm{poq} / \mathrm{nfno}_{5} 6$

Wojcieszak, M., \& Price, V. (2009). What underlies the false consensus effect? How personal opinion and disagreement affect perception of public opinion. International Journal of Public Opinion Research, 2I, 25-46. doi:Io. I093/ijpor/edpoo I

Zou, X., Tam, K.-P., Morris, M. W., Lee, S., Lau, I. Y.-M., \& Chiu, C. (2009). Culture as common sense: Perceived consensus versus personal beliefs as mechanisms of cultural influence. Fournal of Personality and Social Psychology, 97, 579-597. doi:ı. го37/аoor6399

\section{Biographical Notes}

Léila Eisner is a researcher in social psychology at the University of Lausanne, Switzerland. Her research interests relate to attitude measurement, social norms, and collective action.

Dario Spini is full professor of social psychology and the life course. He is also Director of the Swiss National Center of Competence in Research LIVES. His research is interested in how individuals and groups cope with life events and social change and how normative contexts shape their attitudes and behavior.

Nicolas Sommet, Ph.D., is an early career social psychologist working at the University of Lausanne, Switzerland. His main research interest focuses on the psychological consequences of income inequality as well as the conceptualization of achievement motivation. 